\title{
Aprendizaje e Historización: Aportes de la teoría psicoanalítica a la comprensión de dificultades de aprendizaje en niños que han vivenciado procesos de institucionalización y adopción
}

\author{
Learning and Historization: Contributions of psychoanalytic theory \\ to the understanding of learning difficulties in children who have \\ experienced processes of institucionalization and adoption
}

\author{
Daniela Fernández Olguín \\ Escuela de Ciencias Jurídicas y Sociales, Universidad Viña del Mar \\ Correo electrónico: daniela.paz.f@gmail.com
}

\begin{abstract}
RESUMEN
El siguiente artículo tiene por objetivo analizar las dificultades de aprendizaje a partir del concepto de historización que propone la teoría psicoanalítica en el caso de niños que han vivenciado experiencias de institucionalización y adopción. A través de la revisión del caso de una menor que creció en el contexto de una institución de menores y fue adoptada por una familia, se propone la integración de los aspectos subjetivos e históricos en la comprensión y análisis de las dificultades de aprendizaje, considerando existen aspectos psíquicos vinculados al trabajo de historización del estudiante que organizan su relación con el aprender, por lo cual es un elemento de análisis relevante en el estudio e intervención de casos con problemáticas de aprendizaje.
\end{abstract}

Palabras claves: psicoanálisis, dificultades de aprendizaje, simbolización, adopción, constitución psíquica

\begin{abstract}
The aim of this article is to analyze learning difficulties based on the concept of historization proposed by psychoanalytic theory in the case of children who have lived through experiences of institutionalization and adoption. Through reviewing the case of a minor who grew up in the context of a children's institution and was adopted by a family, it is proposed the integration of the subjective and historical aspects in the understanding and analysis of the learning difficulties, considering the fact that there are psychic aspects linked to the student's historization process that organize their relationship with learning, which is why it is a relevant analysis element in the study and intervention in learning problems.
\end{abstract}

Key words: psychoanalysis, learning difficulties, symbolization, adoption, psychic constitution 


\section{APRENDIZAJE Y PSICOANÁLISIS}

Los problemas en el aprendizaje representan un tema de abordaje y preocupación recurrente dentro de las intervenciones en la escuela. Si bien se han establecido criterios particulares para la definición de los diversos trastornos del aprendizaje (American Psychological Association, 2014), en muchas ocasiones las características de las problemáticas de aprendizaje son difusas, siendo construidas desde las observaciones conductuales de docentes y padres, así como a partir de evidencias cuantitativas como las calificaciones, las cuales se convertirían en una primera señal de alerta frente al fracaso escolar:

Esta preocupación se expresa, por un lado, en la gran demanda de atención clínica referida a los problemas de aprendizaje en la infancia, así como en el malestar que esto produce a nivel del consultante, del grupo familiar y de la institución escolar. Por otro lado, desde la asesoría e intervención psicológica en ámbitos educativos, se comprueba cómo la labor de enseñanza-aprendizaje a cargo de los docentes no es una empresa fácil, causando incluso dificultades en la salud laboral docente (Palma \& Tapia, 2006: 96).

Frente a estas problemáticas, se han organizado diferentes discursos que buscan definir, así como intervenir en estas situaciones, siendo estos construidos desde la pedagogía, psicopedagogía y psicología (Szyber, 2009). Algunos de estos discursos tienden a promover una visión más bien individual de la problemática, en la cual las dificultades de aprendizaje responden a una falla del estudiante en la apropiación de los contenidos expuestos, por diversos motivos. De este modo, la atención hacia estas dificultades promueve una intervención focalizada mayormente en el estudiante, si bien se propone la integración de factores vinculados a la escuela, como las estrategias de aprendizaje y condiciones contextuales y políticas de la institución, como infraestructura, número de alumnos y condiciones laborales de los docentes (Szyber, 2009).

Dentro de estos discursos, la teoría psicoanalítica ha buscado integrar en sus análisis los componentes psíquicos que están vinculados al proceso de aprendizaje, definiéndolo como el proceso por el cual un sujeto se apropia de una realidad a través de su experiencia personal, histórica y deseante, transformándola y transformándose en esa misma apropiación (Fernández, 2000). De este modo, se considera el aprendizaje como parte del proceso de constitución vital de un sujeto, que no se circunscribe sólo a lo escolar, y en donde es posible considerar que lo escolar corresponde a uno de los tantos espacios en los cuales el sujeto aprendiente pone en juego su historia y deseo.

Para la perspectiva psicoanalítica el síntoma constituye un fenómeno subjetivo que no se entiende como el signo de una enfermedad, sino más bien como la expresión de un conflicto inconsciente. Entonces, se puede referir que el síntoma refiere también a un saber, del cual el sujeto, dice no saber nada, pero que en el transcurso de la intervención comienza a desplegarse: "Expresa un cumplimiento de deseo y la realización de un fantasma inconsciente que sirve a tal cumplimiento. El síntoma no es el no aprender como el negativo del aprender, sino que lo constituye como significado" (Palma \&Tapia, 2006: 103).

Desde este enfoque, según Palma y Tapia (2006), los problemas que se dan en el aprendizaje en muchos casos evidencian fracasos en la constitución simbólica infantil, que se estructura al interior de la familia y se espera que se despliegue en la escuela, constitución fundamental en la construcción del sujeto. El trastorno del aprendizaje puede 

DIFICULTADES DE APRENDIZAJE EN NIÑOS QUE HAN VIVENCIADO PROCESOS DE INSTITUCIONALIZACIÓN ...

ser considerado como una inhibición del pensamiento, pensando que: "el inconsciente no está constituido desde los orígenes, sino que es producto tanto de la relación con el otro como de la represión. Desde esta perspectiva, un problema de aprendizaje no siempre será una inhibición o un síntoma, pudiendo también ser la expresión de un problema en la constitución misma del psiquismo" (Palma \& Tapia, 2006: 98). El aprender, entonces, forma aparte de un proceso que implica los primeros años de vida, y no sólo el ingreso al mundo escolar, proceso que además conlleva el despliegue de un proceso sumamente importante en la constitución subjetiva, como lo es la simbolización:

La simbolización se lleva a cabo a partir de un corte, de una separación. Se representa al objeto perdido y así el deseo se constituye como movimiento de re-encuentro. Se simboliza la falta, la carencia, la ausencia. Pero es a partir de Winnicott que algunos autores han señalado (Green, Golse, Roussillon) la necesaria calidad de la presencia del otro, de sus cuidados, de su buena compañía, como condición para los procesos de simbolización (Barreiro, 2005: 7).

A través de la falta propia del lenguaje, el niño se inscribe en la dimensión del deseo y así desplazará su deseo en distintos objetos metonímicos y metafóricos, por los cuales intenta desplegar una respuesta en torno a esta falta, movilizándose y movilizando su deseo en estas instancias, movilizado por otro significativo. De este modo, es posible considerar que todo deseo, en tanto movimiento, implica la búsqueda de un objeto, el aprehender distintos objetos que busquen poner un símbolo a esta falta, tomando lugar el lenguaje, que buscará facilitar la inscripción del sujeto en tanto sujeto deseante que gracias al lenguaje recubre esta falta, pero no logra suplirla. De este modo, el deseo implicará de alguna forma u otra siempre un deseo de saber, de buscar y de aprender.

El deseo de saber surge de este modo como un concepto particular, el cual se instituye en el proceso de constitución del sujeto dividido en sus orígenes:

Desde los primeros años de su vida, el niño se lanza a la exploración de su cuerpo y de su entorno, parte hacia el descubrimiento de sí mismo y del mundo que lo rodea para asegurarse su dominio. Lo habitan el deseo de saber, la necesidad de comprender que se prolongarán en las innumerables preguntas que planteará después. La curiosidad, el placer del descubrimiento, la adquisición de conocimientos forma parte de la dinámica de su vida (Cordié, 1994: 29-30).

Las preguntas y las vacancias del conocimiento que el niño va enfrentando desde los primeros momentos de su vida y en las cuales acude a otro con el cual busca enlazar el lenguaje con su aprender. Este enlazamiento se dará en el transcurso de toda la infancia y continuará hasta la adolescencia y adultez, siendo constitutivos los primeros momentos en los cuales se da este vinculo de saber y falta con el otro mediador: "Del aprendizaje por el juego debe pasar, en el transcurso de la infancia, a otra forma del saber, el que dispensa la escuela. Con frecuencia éste es el momento en que la mecánica se engrana, hay una pausa, un rechazo inconsciente a aprender, a entrar en ese nuevo sistema de adquisición de conocimientos" (Cordié, 1994:30).

De este modo, el síntoma surge como una modificación patológica de las funciones psíquicas vinculadas al aprendizaje. Por esto, el saber y el aprender responden a coordenadas históricas del estudiante: 
El saber que el aprendiente tiene y con el cual transforma el saber del otro, son sus preguntas y la posibilidad de ser respondidas. El saber entrega las marcas de lo que falta. (...) Opondrá así, a la falta de respuestas totales - pero sí parciales- de parte de los padres, la posibilidad de aprender de otros, con otros, por competencia y por amor. Sólo esto le posibilitará dirigir la mirada a otro lugar, a la escena pública que constituye, en un primer momento, la escuela (Palma \& Tapia, 2000:104).

Este proceso se desarrolla desde los inicios de su vida, con sus figuras más primarias, las cuales se constituyen y articulan a través de los procesos de historización. Piera Aulagnier define la historización como un trabajo psíquico que "Es una necesidad de su funcionamiento situarse y anclar en una historia que sustituye un tiempo vivido-perdido por la versión que el sujeto se procura merced a su reconstrucción de las causas que lo hicieron ser, que dan razón de su presente y hacen pensable e investible un eventual futuro" (Aulagnier, 1984: 15).

Esta construcción será parcial, fragmentada y selectiva, ya que el sujeto construye su propia versión de su pasado, sus orígenes y su saber, anticipado por otros significativos, que se conceptualización como las figuras cuidadoras en su infancia: "La actividad historizante origina, a partir de la puesta en juego de relatos narrativos y/o escritos historizados, trabajos de subjetivación de la experiencia y movimientos de reescritura que potencialmente suplementan la trama actual de representaciones construidas acerca del pasado" (Grunin, 2008: 3).

A partir de esto, es posible conceptualizar el proceso de historización como un proceso particular y fundante en la relación que el sujeto tiene con el aprendizaje, en tanto, la función del aprendizaje comienza desde la constitución del proceso historizante, del aprender la propia historia del sujeto. En base a esto, el proceso historizante que moviliza el proceso de aprendizaje se funda como particular y vinculado a la propia historia y modo de apropiación que el sujeto hace durante su infancia. Por consiguiente, es posible plantear que todo sujeto para poder comprender y aprender su mundo se cuenta una historia que sea capaz de integrar los diferentes discursos que se le transmiten en una trama histórica con sentido (Ricoeur, 2008).

En la primera infancia, este trabajo es vehiculizado por otro que ayude a elaborar la continuidad y discontinuidad propia de la historia, a través del lenguaje y lo simbólico, que funda la posibilidad de que emerja aquello que podemos llamar historia de vida. Por lo tanto, el aprender se encuentra mediado por otro, quien al inicio se representa por los padres o cuidadores y que posteriormente se corporizan en la cultura escolar por los docentes, testigos de este proceso complejo que en muchas ocasiones queda encapsulado en el mero acto de aprender como reproducción, o en la evidencia del aprender a través de la calificación o nota, cuando subyacen a este proceso las funciones psíquicas descritas.

Por esto, el proceso de aprendizaje adquiere particularidades y aspectos críticos a partir de la función de historización del sujeto aprendiz o estudiante.

\section{SUBJETIVIDAD, INSTITUCIONALIZACIÓN Y ADOPCIÓN}

El contexto de la infancia en Residencias u Hogares ha sido un tema de discusión durante el último tiempo. Frente a esto, es relevante plantear qué definiría a un infante para 

DIFICULTADES DE APRENDIZAJE EN NIÑOS QUE HAN VIVENCIADO PROCESOS DE INSTITUCIONALIZACIÓN ...

ingresar a una institución. Como refiere Janin (2015), ser niño o niña implica estar inscrito simbólicamente en una red de significantes socioculturales en el cual se les otorga un lugar en donde discursivamente pueden advenir. En consideración de esto, en Chile el año 1929 se propone que el Estado debe "dar protección a la infancia denominada en situación irregular (Farías, 2002: 85), siendo el concepto "irregular" confuso, en tanto alude a una normativa que no es equivoca ni única en la infancia. Por estas dificultades, el año 1990 se integra a esta legislación la Convención Internacional sobre los Derechos del Niño, donde "se promueve la protección integral de los derechos del niño" (Farías, 2002: 85).

Dentro de estas leyes se estipulan acciones particulares frente a situaciones irregulares de niños y niñas, dentro de las cuales se describe el ingreso a un Hogar de Menores, el cual es resultado de la puesta en ejecución de las llamadas "medidas de protección" que pueden determinar los Jueces de Familia, "de acuerdo a los informes entregados por asesores técnicos que consideran circunstancias individuales, familiares y sociales para cada caso" (Farías, 2002: 85). El Servicio Nacional de Menores (SENAME) es quien debe velar la aplicación y cumplimiento de estas medidas, a través del trabajo de instituciones de índole privada que constituyen la red SENAME, siendo una de estas instituciones los Hogares de Preescolares y Lactantes (Córdova, 2011).

De este modo, el ingreso de un niño a un Hogar supone que se han efectuado vulneraciones graves a sus derechos por parte de los padres o adultos responsables de su cuidado. Pero, el ingreso a un Hogar de protección implica una doble vulneración: el niño es separado afectivamente de sus figuras significativas y al mismo tiempo porta el daño producido por las situaciones de vulneración (Marchant, 2015). El niño y niña pasan a ser sujetos portadores de un daño producido por situaciones que han transgredido sus derechos, situaciones que son habitualmente silenciadas y que viven en la soledad, por lo que "quedan a merced de las propias sensaciones y exigencias internas (...) no hay mundo representacional a construir (...) lo que se produce es un desfallecimiento precoz de las envolturas y una imposibilidad de elaborar la ausencia en tanto no hubo sostén ni presencia materna" (Janin, 2011: 225-226).

Como refieren Córdova (2011) y Marchant (2015), el ingreso a un hogar plantea a su vez la permanencia e inscripción de otras formas de violencia: la vida cotidiana en el Hogar instaura la acomodación a normas y formas de organización institucional que hasta el momento son ajenas a los niños y niñas "como sede de ceremonias mínimas que hacen posible que la institución opere" (Minnicelli, 2008: 6). El lactante o preescolar se transforma en objeto de una serie de cuidados y rutinas establecidas en que participan niños, niñas y quienes trabajan y viven en el Hogar: no es sólo el ofrecimiento de protección, sino que también el ofrecimiento a ideologías, prácticas y dinámicas que instauran los adultos encargados del funcionamiento del Hogar (Marchant, 2015).

El Hogar, desde el ámbito jurídico, busca ofrecer reparación con el fin de restituirle al niño y niña sus derechos. Si bien este trabajo implica un esfuerzo significativo de la institución y profesionales a cargo, quienes en muchas ocasiones trabajan en condiciones de precarización laboral, esto no finaliza el tema de la reparación en tanto esta noción también debe considerar la subjetividad de cada niño y niña que ha vivenciado experiencias traumáticas, las cuales por su dificultad y dolor asociados buscan no ser retomadas, sino más bien "dejadas en el pasado", como si este pasado pudiera ser omitido en una nueva vida a partir del ingreso al Hogar, y posteriormente a partir de la adopción. Se espera entonces que en este proceso la institución no sólo sea capaz de dar satisfacción a las 
necesidades básicas humanas de los niños y niñas, sino que además ofrecer contención emocional y una elaboración de la experiencia en su vida, mediante el trabajo de historización (Marchant, 2015).

El proceso de reparación se define como una intervención que busca ayudar al niño y niña a integrar su historia vital y elaborar las vulneraciones que sufrió (SENAME, 2013). En lo concreto, esta idea es llevada a la práctica a partir de los llamados "lineamientos técnicos" que buscan formular de manera concisa las prácticas a la base de cualquier programa o intervención que tenga relación con la protección y cuidado de la primera infancia. Estos lineamientos, según Córdova (2011), han sido analizados de manera crítica en cinco puntos relevantes: la familia definida como un grupo fundamental de la sociedad, promoviendo en la intervención la responsabilidad parental y la mejora de las condiciones familiares, pero, se observa que los padres tienen un mínimo de participación en la crianza y educación de sus hijos e hijas al interior de la Residencia (Centro de Derechos Humanos, 2008). Así, la educación y formación del niño y niña institucionalizado está sujeta a preferencias de la Residencia.

Por otro lado, se cuestiona el carácter de transitoriedad de la separación, con el fin de que la institucionalización sea una contribución a la reparación de los derechos de estos niños y niñas en el tiempo más breve posible, pero: "Para el año 2010, del total de niños y adolescentes viviendo en una Residencia, el promedio de permanencia es de 2,7 años, sin presentar grandes cambios" (Córdova, 2011). Como tercer punto, se exponen las dificultades en la metodología o mecanismos que operen desde que el niño y niña ingresan y que sean capaces de dar cuenta de un diagnóstico inicial y la fijación de objetivos a mediano plazo. Además, se reconocen que "los cambios continuos del ambiente donde se dan los cuidados son perjudiciales para el desarrollo del niño/a y su capacidad de formas apegos" (Departamento de Protección de Derechos, 2007, p.5), esto implica una dificultad en tanto el personal de trato directo (cuidadoras/es-educadoras/es) no tienen una participación sistemática en las instancias de coordinación y planificación formales, siendo esto contraproducente ya que son las figuras que mantienen los vínculos más estrechos con los niños, siendo los encargos de resolver todo tipo de conflictos y proporcionarles todos los cuidados para su bienestar.

Finalmente, es fundamental el análisis de las observaciones realizadas a los equipos de trabajo que se desempeñan en estas instituciones: "equipos desgastados, insuficientemente capacitados, y que se encuentran superados por la realidad actual de niños y niñas, trabajando muchas veces en condiciones precarias" (Martínez, 2010: 65).

Tales condiciones en los procesos de subjetivación de los niños y niñas constituyen la historia previa de los niños, antes de su potencial adopción y abandono de la Residencia, historia que no encuentra espacios de elaboración propios ya que "es relevante destacar que en la medida de que el niño/a sea mayor de 7 años, se sugiere que el terapeuta de mayor énfasis al uso del lenguaje simbólico y explicativo como herramienta de significación de la experiencia, ya que la reformulación narrativa ocurre de manera más clara en niños escolares" (SENAME, 2011: 4), dejando para los niños y niñas más pequeños un trabajo enfocado en el autocontrol emocional con el fin de prepararse para posibles situaciones de estrés afectivo, como la incorporación a una nueva familia, sin considerar aspectos simbólicos elaborativos para niños menores de 7 años (Córdova, 2011).

El proceso de adopción y salida de la Residencia no está exento de complejidades. Los requisitos expuestos por el Servicio Nacional de Menores (2010b) son diferenciales 

DIFICULTADES DE APRENDIZAJE EN NIÑOS QUE HAN VIVENCIADO PROCESOS DE INSTITUCIONALIZACIÓN ...

para personas de nacionalidad chilena y extranjeras, solicitando residencia en Chile, edad entre 25 y 60 años, diferencia de edad con el menor adoptado de por lo menos 20 años, en el caso de matrimonios tener al menos 2 años casados (esto no se exige en el caso que uno o ambos cónyuges sean infértiles), evaluación psicológica y social, participación en taller de información y entrevista posterior. Si el resultado de la evaluación es favorable, se ingresan al registro de personas residentes en Chile interesadas en adoptar a un niño o niña, de acuerdo a lo prescrito por el artículo 5 de la Ley $\mathrm{N}^{\circ} 19.620$. El período de asignación de un niño o niña es de 18 a 24 meses aproximadamente, y en la etapa de espera las personas cuentan con un período de acompañamiento de parte de los profesionales la Unidad Regional donde se ha efectuado el proceso, que consiste en encuentros y talleres pre-adoptivos.

Cuando se ha ingresado un niño o niña en condiciones de ser adoptado a la Unidad de Adopción respectiva, se ubica entre los postulantes "la mejor alternativa de familia para él/ ella" (SENAME, 2010b, s/p). En base a esto, se propone formalmente al Tribunal la opción seleccionada mediante una terna o de manera individual. Si el Tribunal decide a favor de la familia, el niño o niña es propuesto a ella y si la familia acoge esta proposición, se planifica el encuentro con el niño o niña para luego comparecer ante el Tribunal de Familia para solicitar su cuidado personal. Si el Tribunal confía la entrega del cuidado personal a la familia, se inicia el trámite para concretar la adopción ante el Tribunal de Familia. En caso que la familia decida no acoger la propuesta de Sename, la postulación continua en proceso. Finalmente, se realizan actividades de seguimiento del niño o niña y la familia adoptiva, como visitas domiciliarias y talleres post-adoptivos.

Como se describe, el proceso implica diferentes pasos y complejidades, si bien se ha modificado la ley para que el proceso sea más simple, surgen en sus etapas potenciales dificultades, como que la familia de origen reclame la custodia del menor durante el proceso de adopción, el alto costo para la familia interesada del proceso, o que finalmente el proceso no llegue a fin, luego de que ya han conocido y se han vinculado con la familia interesada. Se menciona a su vez, los casos en que niños y niñas son "devueltos" a los centros de acogida del SENAME, siendo los menores expuestos a un doble rechazo. Si bien en la actualidad se busca continuar en la mejora del proceso con el fin de prevenir estas dificultades, aun quedan tareas por realizar para esto.

Los efectos de esta realidad institucional implican la comprensión de que el Hogar no es sólo un lugar donde se encuentran niños privados de cuidado parental, sino un lugar donde se articulan dinámicas subjetivas e intersubjetivas que son parte de la historia del niño en su posible adopción. La Residencia para los niños y niñas es "lo que tienen a mano, lo que está inmediatamente a su disposición, es la principal referencia como realidad (...) es posibilitante, es decir, les ofrece posibilidades, modos de estar en el mundo" (Martínez, 2010: 87). Así, la vivencia de niñez temprana en este contexto posee implicancias subjetivas relevantes en torno a los procesos psíquicos e intersubjetivos del niño y niña con otro, condiciones que responden a un bagaje e historia que el niño corporiza y que se desenvuelven no sólo en su mundo interno y familiar, sino también en su mundo escolar.

En este caso se indagará en torno a las particularidades propias y propuesta de análisis para un caso de una menor de 6 años que fue adoptada luego de vivir hasta los 4 años y medio en una residencia del Servicio Nacional de Menores, y quien presentaba dificultades de aprendizaje en el contexto escolar. 


\section{EL CASO DE ANTONIA: SUJETO DE HISTORIA EN EL APRENDER ${ }^{1}$}

Antonia tiene 8 años, cursa Tercero Básico en un colegio mixto particular y es hija adoptiva de una pareja con quienes convive desde hace un año y medio, viviendo los tres en el hogar. Anteriormente, la niña estuvo en un Hogar de Menores perteneciente al SENAME, desde los 2 años de edad. En esa Institución, en condición de susceptibilidad de adopción, conoce y se vincula afectivamente con sus actuales padres adoptivos; habiendo recibido terapia de reparación en SENAME.

Este caso es trabajado en el marco de la atención clínica particular, con sesiones regulares $1 \mathrm{vez}$ a la semana, debido a solicitud de la profesora de Antonia hace a los padres, ya que la alumna presentaba calificaciones deficientes, poca motivación por el estudio y poca tolerancia a la frustración. Se expondrán algunos antecedentes que se plantearon en los primeros 2 meses de tratamiento, durante la fase de conocimiento de la problemática.

En la primera entrevista con la madre, señala que Antonia habría resultado muy afectada por sus experiencias con su familia de origen, daño que, a su juicio, no ha sido elaborado por la niña. Esta situación provocó tristeza en los padres adoptivos, asociado a sentimientos de culpa respecto de no haber podido proteger a la niña del maltrato que vivenció. En base a que la problemática de la niña se ha presentado desde aproximadamente un año, y como sugerencia del colegio, comenzó a asistir de forma de mensual a neurólogo, donde fue diagnosticada con un Trastorno Oposicionista Desafiante.

Actualmente, Antonia realiza actividades escolares mostrándose muy disruptiva en aula y desordenada. Se observa muy ansiosa en contexto escolar, y sus docentes y padres se preocupan porque su rendimiento académico se ha visto cada vez más descendido con el transcurso del año escolar. Demuestra interés por actividades artísticas, donde permanece concentrada y entusiasmada. Tiende a preferir juegos bruscos con sus compañeros.

En la primera entrevista realizada con la niña, Antonia establece un contacto amistoso, siendo curiosa, muy cariñosa, con poca tolerancia a frustraciones. Antonia mezcla en su discurso recuerdos de sus diferentes vivencias en instituciones y experiencias familiares, así como sus propias fantasías respecto al proceso de adopción, por ejemplo, diciendo que una de sus prendas de ropa favoritas fue regalado por sus padres biológicos. Frente a estas ideas, los padres refieren preferir no decir nada por temor a desilusionar a Antonia.

Antonia describe una dinámica familiar armónica, refleja en el discurso que se siente querida y aceptada por sus padres, con quienes disfruta compartir. En entrevista con los padres, se refiere que muchas veces se sienten superados por el comportamiento de Antonia, describiendo que en una ocasión amenazaron a la niña diciéndole que la devolverán al Hogar si sigue teniendo malas notas, lo que incrementa su ansiedad, ya que en las ocasiones que Antonia ha presentado un peor comportamiento, ha existido el antecedente de este tipo de retos por parte de los padres.

\section{EL LUGAR DE LA HISTORIZACIÓN EN EL APRENDIZAJE DE NIÑOS QUE HAN VIVENCIADO PROCESOS DE INSTITUCIONALIZACIÓN Y ADOPCIÓN}

A partir de los elementos expuestos en la viñeta, se realizará una propuesta de análisis en torno al concepto de historización y su posible lugar en las dificultades de aprendizaje en

Datos y contexto del caso y de la situación han sido alterados con el fin de mantener la confidencialidad. 

DIFICULTADES DE APRENDIZAJE EN NIÑOS QUE HAN VIVENCIADO PROCESOS DE INSTITUCIONALIZACIÓN ...

estos contextos. El trabajo de historización conlleva una actividad subjetivante que articula el tiempo pasado y presente de modo particular, para así re-situarse en torno a nuevas formas de interpretar el tiempo pasado, con el fin de poder proyectarse a un futuro (Grunin, 2008). De este modo, la apropiación, el aprender y el aprehender la propia historia de vida es una acción fundante que posibilita la constitución de la subjetividad durante la infancia, la cual se encuentra vehiculizada por otro adulto, quien es testigo de la realidad histórica y psíquica de la niña, insertándola en una trama histórica, que lo sostenga, ahí donde han quedado marcas de dolor (Janin, 2011).

La experiencia de institucionalización para una niña, así como el proceso de adopción, implica un proceso difícil, pero a la vez relevante, en el sentido de que implica el poner en juego el deseo de aprender de su propia historia, retomando situaciones vivenciadas en el hogar y en su vinculación con sus padres adoptivos. De este modo, es un trabajo que implica un nivel de dolor y sufrimiento, el cual se hace necesario en tanto se reconocen los sucesos vivenciados y articuladores de los años tempranos (Marchant, 2015).

La confusión respecto a su propia historia puede comprenderse como un impasse en los procesos del aprender, respecto a las posibilidades que se juegan en la constitución de la propia historia personal y procesos de subjetivación, versus, la demanda respecto al aprender contenidos externos transmitidos por otro no familiar. Tal complejización pude verse con Antonia, en tanto, mostrando un adecuado desempeño cognitivo desde los parámetros psicométricos, no podía vivenciar el deseo y la falta de un modo movilizante, sino que más bien buscando actuar la culpa respecto a sentirse excluida en otro ámbito respecto a un conocimiento compartido.

Se constituye como síntoma para Antonia el modo en que busca resolver el enigma respecto a sentir que no le es permitido aprender su propia historia: "El secreto produce violencia sobre quien lo padece y sobre quien lo ejecuta, coartando la autoría del pensamiento. Mientras que lo reprimido es elaborable, lo ausente, a partir del secreto, queda fuera del alcance de la elaboración. No todo puede decirse, no todo puede simbolizarse, ya que siempre queda un resto" (Palma y Tapia, 2000, p.104). El secreto facilita dificultades en la simbolización y a la historización de ciertas historias: al aprender ciertas vivencias e inscripciones en la continuidad psíquica, que se instituyen como trauma, en tanto no son elaboradas ni integradas por la niña, debido a que -por el momento del desarrollo en que la situación de vulneración ocurre- requiere de otro que pueda promover y ayudar en esta tarea historizante.

Los niños entonces no solamente construyen su historia para su propio fin, sino que son parte de una cadena generacional, en la que representan un eslabón más como heredero del conjunto intersubjetivo en una lógica que va más allá de la concepción de herencia biológica: "Como seres humanos, en cualquier época y sociedad, estamos impulsados por representaciones extremadamente persistentes, transmitidas de generación en generación, provenientes de nuestros lejanos ancestros (...)" (Héritier, 2007: 166).

A pesar de que no hay transmisión que no sea siempre de una u otra manera transformada por la capacidad de elaboración individual, se constituye como central la relación entre el grado de capacidad de contención y elaboración del yo, y la intensidad de la presencia del otro en estas transmisiones, ya que no es posible pensar la transmisión ni el secreto si no es en la consideración de un grupo familiar o social como nudo colectivo en el cual el sujeto toma su posición (Corigliano, 1993). Por esto, la transmisión en las dificultades de aprendizaje debe considerar también los aspectos intersubjetivos en los cuales la niña se ha desenvuelto, a nivel institucional, familiar y escolar. 
A partir de esto, es posible problematizar en torno a al desenvolvimiento del aprendizaje no sólo en el espacio escolar, sino como función desde los inicios de la construcción subjetiva de las personas. Su historia vital, relatada en la presentación del caso, da cuenta de ciertos momentos en los cuales los vacíos y las faltas se van inscribiendo como un modo de aprender la realidad y su propia historia, donde el temor de "hacer más daño" se articula como discurso para no volver a re-presentar el pasado, pensando que el problema de aprendizaje no tiene que ver con su historia vital. La constitución subjetiva es un proceso doble, humanización y sexuación: proceso historizante y resignificación de lo sucedido a simbolizar que va más allá de una temporalidad cronológica.

La historia de cada niño y niña está atravesada por el poder aprender, a partir del ambiente, su propia constitución y elaborando estos elementos con la facilitación de otro mediador. Pero en los casos en que este otro teme expresar la historia y busca entonces mantener en secreto ciertos ámbitos por ser dolorosos para la niña -y también para los propios padres, como el sentimiento de culpa de no haber podido defender a Antonia del maltrato que sufrió-, se produce un detenimiento y el vacío busca ser llenado con la sintomatología descrita, como modo de actuar la culpa y actuar también un pedido y un auxilio hacia las figuras adultas, como modo de comprender la constitución de la propia niña como sujeto inscrita en cierta cadena familiar y de significantes: se puede referir que hay algo que Antonia y sus padres prefieren no saber, porque al mismo tiempo lo saben.

Con el ingreso a la escuela, este pedido no sólo es hacia los padres, sino que comienza a reproducirse en las figuras docentes o enseñantes, repitiendo estas demandas en el ámbito escolar de forma particular. De este modo, aparece como sintomatología la dificultad de aprendizaje, la cual se organiza en la escuela, pero también incluye elementos subjetivos de Antonia, más allá de la internalización de contenidos cognitivos, sino parte de la construcción de su subjetividad.

La puesta en discurso de esta historia, mediante el proceso de simbolización de estas experiencias que han sido silenciadas y no elaboradas, es un trabajo relevante en este contexto, en tanto es una primera instancia de aprendizaje de la niña. Los discursos que se construyan y que se ofrezcan a la niña en torno a su problemática van a ser relevantes en la organización identitaria que la niña realiza sobre si misma, así como en su trabajo de historización ya que: "para el niño, asumirán importancia las palabras pronunciadas por quienes lo rodean acerca de su enfermedad. Esas palabras o su ausencia crearán en él la dimensión de la experiencia vivida. También la verbalización de una situación dolorosa le permitirá dar un sentido a lo que vive" (Mannoni, 2007: 65).

Este trabajo de historización necesario para poder instaurar el deseo de aprender, la posibilidad de articular un deseo en torno a una falta, no es una tarea fácil, menos en estas situaciones en las que este trabajo demanda retomar situaciones traumáticas y dolorosas, para la niña y su familia. El reconocimiento de su propia historia requiere un reconocimiento de este suceso, trabajo que no está exento de dolor para la niña y sus padres, pero que no se puede negar aquello de ese "saber que ha quedado en la memoria individual del sujeto" (Mannoni, 1992: 58) y que se busca silenciar y poner en un lugar "pasado", como eventos sin relación con la vida actual de la niña.

Cuando esta memoria se llena con vacíos o mentiras, no se respeta la historia de la niña ni se trabaja por la verdad: "ningún duelo puede efectuarse con relación a una historia que fue transmitida bajo la forma del silencio o de la mentira" (Calvi, 2008). Se deja a la niña huérfana nuevamente, pero esta vez de palabras ya que el silencio acarrea secretos y un no 

DIFICULTADES DE APRENDIZAJE EN NIÑOS QUE HAN VIVENCIADO PROCESOS DE INSTITUCIONALIZACIÓN ...

saber (Eliacheff, 2002). Si se instituye una lógica de no saber respecto a la vida, puede ser esperable que esta lógica permanezca y se desenvuelva en otros espacios del saber.

Esta lógica se mantiene en muchas ocasiones por la idea de "proteger" a la niña de recordar estos eventos traumáticos y dolorosos: "la tendencia general sigue siendo ya la de no decir nada (son demasiado pequeños para comprender), ya la de negociar o de minimizar los hechos (papá está de viaje, mamá va a volver, él o ella, no lo hizo a propósito)" (Eliacheff, 1994: 59-60).

De este modo, historizar el daño producido, así como la historia de vida de la niña puede instaurar lo simbólico en un ámbito en el cual se muestra y se habla de otros, función psíquica que acompaña a su vez los procesos de aprendizaje. Surge de este modo la pregunta ¿cómo podemos esperar que un niño o niña aprenda contenidos transmitidos por otro social si no se le ha posibilitado la instancia de aprender su propia vida? Posibilitar en estos casos este trabajo y conceptualizarlo como relacionado con los problemas de aprendizaje abre una nueva perspectiva en la comprensión de la subjetividad de los niños y niñas que han vivenciado experiencias de institucionalización y sobre lo que se comprende o define como aprender, función que no es la mera asimilación de contenidos, sino que implica un trabajo psíquico propio, así como intersubjetivo.

Aludir a esta complejidad en el análisis de las dificultades de aprendizaje conlleva a que el lugar del docente se vea tensionado en esta situación, considerando que Antonia emerge como un sujeto que busca un reconocimiento particular que se despliega en la relación con los docentes: "El tema de la heterogeneidad de los alumnos resume el objetivo del conjunto de las tensiones de la experiencia de los profesores del colegio, en la medida en que las diferencias de nivel de los alumnos llaman a diferencias de métodos y actitudes, y hasta de objetivos" (Dubet \& Martuccelli, 1998: 8). Un trabajo particular de acompañamiento con los docentes y permita la resignificación de la oferta educativa que los enseñantes entregan a Antonia, la cual no deja de estar influenciada por la oferta que la propia institución construye respecto a lo que se entiende por educación.

A partir de esto, la inclusión de un análisis institucional que devele prácticas macroestructurales que participan en la construcción del pivote que es la oferta educativa y que posibilita el enlace entre lo particular del sujeto y lo social, puede ser beneficioso para comprender as prácticas docentes que se dan en el aula. Este vínculo educativo no está exento de los propios vínculos que los enseñantes construyen respecto a la institucionalidad. El sujeto de la educación, como plantea Tizio (2001), es un lugar que se construye, y se construye a partir de la oferta que el otro le ofrezca con el cual puede acceder al mundo:

Se puede pensar el sujeto de la educación como una plaza ofertada para el acceso a la cultura, que se construye en función de unas atribuciones (capacidad y voluntad) supuestas por el agente al sujeto, y por la aceptación de éste a ocupar dicho lugar. Pero esto no sucede sin más, es necesario un trabajo de transmisión por parte del agente y de adquisición por parte del sujeto. El agente debe perfilar un marco que configura los espacios y tiempos del trabajo educativo (Tizio, 2001:6).

Por otro lado, el trabajo grupal a nivel institucional de la escuela puede facilitar la construcción de "una visión dinámica de las situaciones, (...) como totalidad, en su cotidianeidad, en su quehacer, en las relaciones que los individuos mantienen, nucleados por una tarea común que constituye la producción" (Foladori, 2008: 53). 


\section{DISCUSIONES FINALES}

A modo de discusión, se plantean puntos relevantes en el análisis del caso y el trabajo con niños que han vivenciado la experiencia de institucionalización. Si bien en algunas ocasiones se expone que la salida del Hogar o Residencia sería la "solución" frente a la problemática del niño o niña, su inserción a una nueva familia y contexto es complejo, en tanto requiere nuevas elaboraciones, así como pérdidas subjetivas (abandono del Hogar, de la identidad de niño o niña "vulnerado", etc.). Por esto, es necesario ver el abandono del Hogar como un proceso igual de complejo que se ingreso, y que requiere para su elaboración, la previa elaboración de lo que implica el pasaje del ingreso y permanencia en el Hogar. Desestimar esta importancia conlleva a que el niño y niña vivan una experiencia de silencio y una inhibición a la posible simbolización de estas experiencias, siéndole negada su identidad e historia.

El deseo de aprender que se pone en juego en estas problemáticas alude a su vez a la movilización por parte del niño y niña del estatuto de su verdad subjetiva. La identidad del sujeto está construida por el trabajo de historización en el cual se puedan simbolizar aspectos de la vida como un continuo que pueda propiciar la noción de un yo estable, así como su proyección hacia al futuro. Esta historia es la verdad del sujeto, la cual, al querer ser silenciada, con el pretexto de evitar un sufrimiento del niño y niña al recordar aquellas experiencias, niega parte de su identidad y puede implicar un sufrimiento aun mayor en el niño y niña. Por otro lado, se deja entrever una visión en la cual la inserción a un nuevo contexto, como si mágicamente el abandono del Hogar implicara una reparación a todo el proceso vivenciado anteriormente. Si bien este caso es particular y único, es posible generalizar que esta noción es muy difundida en el trabajo con niños que han vivenciado experiencias de institucionalización. Las vivencias previas del niño y niña no son reparadas espontáneamente por el mero abandono del Hogar, sino que son parte de la historia subjetiva del menor y requieren elaboración; en caso contrario, es posible que aquello que se busca silenciar, emerge igualmente como síntoma, en este caso, como una dificultad de aprendizaje. La particularidad de esta dificultad se relacionaría con la constitución del deseo de aprender, que se ha visto inhibido por el mismo funcionamiento que se organiza en torno al deseo de aprender de su propia historia, la cual se ha visto inhibida y negada.

Finalmente, surge como reflexión el desafío que implica para la institución escolar y docentes el trabajo con niños y niñas que traen este bagaje histórico particular, lo cual otorga diversidad al ejercicio pedagógico. El docente es quien corporiza aquel saber que se transmite, cuyo ejercicio no es neutral y que está inscrito en diversas variables contextuales, económicas e institucionales. Este lugar puede ser ocupado si por parte del sujeto aprendiente existen las condiciones psíquicas y temporales para apropiarse de la oferta. La historización de las vivencias de Antonia, a partir de un trabajo que vaya más allá del síntoma entendido como un signo de enfermedad, y más como algo de la verdad de Antonia puesta en juego, podría facilitar este proceso de aprehender la propia historia, así como de simbolizarla de otra manera que implique la puesta en discurso de los vacíos y confusiones, por parte de Antonia y sus padres. 
APRENDIZAJE E HISTORIZACIÓN: APORTES DE LA TEORÍA PSICOANALÍTICA A LA COMPRENSIÓN DE DIFICULTADES DE APRENDIZAJE EN NIÑOS QUE HAN VIVENCIADO PROCESOS DE INSTITUCIONALIZACIÓN ...

\section{REFERENCIAS BIBLIOGRÁFICAS}

American Psychiatric Association. (2013). DSM-5. Manual Diagnóstico y Estadístico de los Trastornos Mentales. Arlington: American Psychiatric Association.

Aulagnier, P. (1984). El aprendiz de historiador y el maestro brujo. Del discurso identificante al discurso delirante. Buenos Aires: Amorrortu Editores.

Barreiro, J. (2005). ¿Qué aprendemos de los niños que no aprenden? Revista de la Asociación Psicoanalítica del Uruguay. Recuperado el 10 de abril del 2017 desde www.apuruguay.org/ revista_pdf/j_barreiro_lo_que_aprendemos_de_los_ninos.pdf

Calvi, B. (2008). El derecho a la infancia. El maltrato y el abuso: modos de destitución de la niñez. En Minnicelli, M. (coord.). (2008). Infancia e institución(es). 103-123. (1a Ed.). Buenos Aires: Noveduc

Centro Derechos Humanos. (2008). Informe anual sobre derechos humanos en Chile 2008. Extraído el día 15 de abril de 2017 desde http://www.derechoshumanos.udp.cl/wp-content/ uploads/2009/07/derechos-nino.pdf

Cordié, A. (1994). Los retrasados no existen. Psicoanálisis de niños con fracaso escolar. Buenos Aires: Nueva Visión.

Córdova, M. (2011). La técnica del libro de vida y sus implicancias: Un trabajo por la historia, memoria e identidad de niños institucionalizados. Memoria para optar al titulo de Psicóloga. Universidad de Chile. Recuperado el 8 de abril del 2017 desde repositorio.uchile.cl/ handle/2250/116698

Corigliano, A. (1993). Lo transgeneracional, entre mito y secreto. Revista Interazoine. 1(96). Recuperado el 10 de marzo del 2017 desde http://www.psicologiagrupal.cl/escuela/index. php?option=com_content \&view=article\&id=238:1o-transgeneracional-entre-mito-y-secreto\&c atid=43:articulos\&Itemid $=69$

Departamento de Protección de Derechos. (2007). Modalidad residencias de protección para lactantes y pre-escolares. Santiago: Sename. Recuperado el 10 de marzo del 2017 desde www. sename.cl/wsename/otros/proteccion/lineamientos/bases_residencia.pdf

Dubet, F. \& Martuccelli, D. (1998). En la escuela. Sociología de la experiencia escolar. Buenos Aires: Editorial Losada.

Eliacheff, C. (1994). El cuerpo y la palabra. Ser psicoanalista con los más pequeños. Buenos Aires: Nueva Visión.

Eliacheff, C. (2002). Del niño rey al niño víctima. Violencia familiar e institucional. Buenos Aires: Nueva Visión

Farías, A. M. (2002). Uso del internado en el sistema de protección en Chile. En Ferrari, M., Couso, J., Cillero, M. \& Cantwell, N. (2002). Internación de niños: ¿el comienzo del fin? 85 -107. (1 ${ }^{\mathrm{a}}$ Ed.). Florencia: Unicef, Centro de Investigación Innocenti.

Fernández, A. (2000). Poner en juego el saber. Psicopedagogía: propiciando autorías de pensamiento. Buenos Aires: Nueva Visión

Foladori, H. (2008). La intervención Institucional. Hacia una clínica de las instituciones. Santiago: Editorial Arcis.

Grunin, J. (2008). Procesos de simbolización y trabajo de historización en la adolescencia. Cadernos de Psicopedagogía. 7(12), Sao Paulo. Recuperado el 8 de abril del 2017 desde http://pepsic. bvsalud.org/scielo.php?script=sci_arttext\&pid=S1676-10492008000100004

Héritier, F. (2007). Masculino/Femenino II. Disolver la jerarquía. Buenos Aires: Fondo de cultura económica de Argentina S.A.

Janin, B. (2011). El sufrimiento psíquico en los niños. Psicopatología infantil y constitución subjetiva. Buenos Aires: Noveduc.

Janin, B. (2015). Intervenciones en la clínica psicoanalítica con niños. Buenos Aires: Noveduc.

Mannoni, M. (1992). Lo que falta en la verdad para ser dicha. Buenos Aires: Nueva Visión. 
Mannoni, M. (2007). El niño, su “enfermedad” y los otros. Buenos Aires: Nueva Visión

Marchant, M. (2015). El libro de vida: Un lugar para la memoria. Santiago: Ediciones Universidad Alberto Hurtado.

Martínez, V. (2010). Informe final. Caracterización del perfil de niños, niñas y adolescentes, atendidos por los centros residenciales de Sename. Chile: Unicef

Minnicelli, M. (2008). Escrituras de la ley en la trama social. Ensayo sobre la relación entre dispositivos, ceremonias mínimas y prácticas profesionales. Revista Pilquen, 5, 1-13.

Palma, E. \& Tapia, S. (2006). De la subjetivación a la apropiación. Aportes del psicoanálisis a los problemas de aprender. Revista de Psicología, 15(2), 95-111.

Ricoeur, P. (2008). La memoria, la historia, el olvido. Buenos Aires: Fondo de la Cultura Económica

Servicio Nacional de Menores. (2010). Adoptar en Chile: Un largo camino para convertirnos en familia. Guía para padres. Santiago: Sename. Recuperado el 22 de abril del 2017 desde www. sename.cl/wsename/otros/adopcion/guia-para-padre-adoptando-en-chile.pdf

Servicio Nacional de Menores. (2011). Bases técnicas. Duodécima convocatoria de concurso público de proyectos para la línea de acción programas de protección especializados. Modalidad: programa de intervención con niños/as institucionalizados y su preparación para la integración a familia alternativa a la de origen (PRI). Santiago: Sename. Recuperado el 21 de abril del 2017 desde www.sename.cl/wsename/licitaciones/p12_19-07-2011/Bases_TEC_PRI.pdf

Servicio Nacional de Menores. (2013). Bases técnicas para la línea de acción Programas de Protección Especializados. Modalidad: Programa de intervención con niños/asinstitucioanlizados y su preparación para la integración a familia alternativa a la de origen (PRI). Santiago: Sename. Recuperado el 1 de mayo del 2017 desde http://www.sename.gov.cl/wsename/licitaciones/ p10_09-05-2013/bases_tecnicas.pdf

Szyber, G. (2009). De la integración a la inclusión, de la inclusión a la escuela para todos. En Wettengel, L., Untoiglich, G., Szyber, G. (2009). Patologías actuales en la infancia. Bordes y desbordes en clínica y educación. 53-75. (1ª Ed.). Noveduc: Buenos Aires.

Tizio, H. (2001). Reinventar el vínculo educativo: aportes de la Pedagogía Social y del Psicoanálisis. Barcelona: Editorial 